\title{
The Role of Relational Binding in Item Memory: Evidence from Face Recognition in a Case of Developmental Amnesia
}

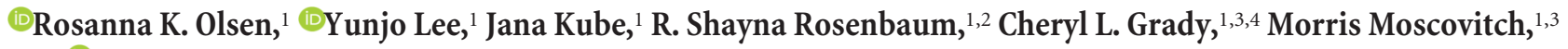 \\ and $\odot$ Jennifer D. Ryan ${ }^{1,3,4}$ \\ ${ }^{1}$ Rotman Research Institute, Baycrest, Toronto, Ontario M6A 2E1, Canada, ${ }^{2}$ Department of Psychology, York University, Toronto, Ontario M3J 1P3, \\ Canada, ${ }^{3}$ Department of Psychology, University of Toronto, Toronto, Ontario M5S 3G3, Canada, and ${ }^{4}$ Department of Psychiatry, University of Toronto, \\ Toronto, Ontario M5T 1R8, Canada
}

Current theories state that the hippocampus is responsible for the formation of memory representations regarding relations, whereas extrahippocampal cortical regions support representations for single items. However, findings of impaired item memory in hippocampal amnesics suggest a more nuanced role for the hippocampus in item memory. The hippocampus may be necessary when the item elements need to be bound within and across episodes to form a lasting representation that can be used flexibly. The current investigation was designed to test this hypothesis in face recognition. H.C., an individual who developed with a compromised hippocampal system, and control participants incidentally studied individual faces that either varied in presentation viewpoint across study repetitions or remained in a fixed viewpoint across the study repetitions. Eye movements were recorded during encoding and participants then completed a surprise recognition memory test. H.C. demonstrated altered face viewing during encoding. Although the overall number of fixations made by H.C. was not significantly different from that of controls, the distribution of her viewing was primarily directed to the eye region. Critically, H.C. was significantly impaired in her ability to subsequently recognize faces studied from variable viewpoints, but demonstrated spared performance in recognizing faces she encoded from a fixed viewpoint, implicating a relationship between eye movement behavior in the service of a hippocampal binding function. These findings suggest that a compromised hippocampal system disrupts the ability to bind item features within and across study repetitions, ultimately disrupting recognition when it requires access to flexible relational representations.

Key words: amnesic; eye movements; faces; hippocampus; memory; viewpoint

\section{Introduction}

Numerous neuropsychological and neuroimaging studies point to a critical role for the hippocampus in memory for associations among distinct items (relational binding) and for medial temporal lobe (MTL) cortices for the items themselves (Cohen and Eichenbaum, 1993; Brown and Aggleton, 2001; Davachi, 2006; Montaldi and Mayes, 2010). However, despite reports of relative sparing of item memory in hippocampal amnesics, significant impairments have been observed (Stark and Squire, 2003; Aly et al., 2010; Smith et al., 2014), necessitating further examination of the relationship between hippocampal integrity and item memory.

Received Sept. 25, 2014; revised Jan. 22, 2015; accepted Feb. 24, 2015.

Author contributions: R.K.O., Y.L., R.S.R., C.L.G., M.M., and J.D.R. designed research; R.K.O., Y.L., and J.K. performed research; R.K.O. and J.K. analyzed data; R.K.O., Y.L., R.S.R., C.L.G., M.M., and J.D.R. wrote the paper.

This work was supported by a Tier II Canada Research Chair award and funding from the Natural Sciences and Engineering Research Council of Canada (NSERC RGPIN 251070-13) to J.D.R. We also acknowledge funding from the Natural Sciences and Engineering Research Council of Canada awarded to R.S.R. (NSERC 2014-06704). We thank Courtney Smith, Maria Ayala, Rida Anmol, and Lingqian Li for assistance with data collection; Jennifer Rabin and Nicole Carson for assistance with neuropsychological testing; and Maria D'Angelo for assistance with data analysis. We also especially thank H.C. for her participation in our research.

The authors declare no competing financial interests.

This article is freely available online through the J Neurosci Author Open Choice option.

Correspondence should be addressed to Dr. Rosanna K. Olsen, 3560 Bathurst Street, Toronto, ON M6A 2E1, Canada. E-mail: rolsen@research.baycrest.org.

DOI:10.1523/JNEUROSCI.3987-14.2015

Copyright $\odot 2015$ the authors $\quad 0270-6474 / 15 / 355342-09 \$ 15.00 / 0$
It has been proposed that hippocampal representations have inherent flexibility, as relations are stored separately from the items themselves, thereby allowing for the retrieval of the constituent elements through multiple routes (Cohen and Eichenbaum, 1993). By contrast, MTL cortex lacks neuroanatomical properties to create flexible memory representations, limiting cortical-based reactivation through subcomponents of the previously stored memories (Eichenbaum et al., 2007). As a result, the formation of and access to cortical-based item representations are limited when items are physically manipulated across presentations. Thus, we propose dual routes to the formation of item memories: one conjunctive/configural representation that is relatively inflexible and supported by the MTL cortex (Bussey and Saksida, 2002; Moses and Ryan, 2006), and a separate relational representation that is flexible, supported by the hippocampus, and contains information regarding relations among features within an item (Jonides et al., 2008) and among item information presented across repetitions (Eichenbaum and Cohen, 2001). We predict that either cortical or hippocampal representations can support memory across identical item repetitions, whereas the latter would be critically required to support performance when instances of an item are varied. Consistent with this notion are findings of impaired recognition in hippocampal amnesic cases for object locations or scenes that have been shifted in perspective 
from the study to test phase (Holdstock et al., 2000; King et al., 2002; Taylor et al., 2007).

The present work examined the extent to which the hippocampus is critical for the development of viewpointindependent item representations, just as it has been shown to be critical for viewpoint-independent spatial representations (O'Keefe and Nadel, 1978). The developmental amnesic case H.C., who experienced abnormal hippocampal and mammillothalamic tract development but presents with volumetrically normal MTL cortex (Olsen et al., 2013), and demographically matched controls were tested on a recognition memory paradigm in which the viewpoints of faces were manipulated across study repetitions and/or at test. If the hippocampus supports the binding of feature relations within an item and/or of multiple, physically manipulated, instances of an item, H.C. should demonstrate recognition impairments when face viewpoints are altered across study and/or test presentations. Eye movement data were obtained during the study phase to provide converging evidence regarding the role of the hippocampus in item memory. If the hippocampus supports the binding of features within items, differences in the visual sampling of - and transitions among - facial features between H.C. and controls should be observed. Such findings would reveal the conditions under which the hippocampus plays a critical role in item memory.

\section{Materials and Methods}

Participants. H.C. is a woman with developmental amnesia, aged 23 at the time of testing. H.C.'s bilateral hippocampal volume is significantly reduced $(29.5 \%$ on the left and $31.2 \%$ on the right) compared with a group of age-matched, sex-matched, and education-matched controls (Olsen et al., 2013). H.C.'s MTL cortices, on the other hand, are volumetrically normal. In fact, her left parahippocampal cortex was found to be marginally larger than that of the control group. While it was previously assumed that H.C. experienced a perinatal hypoxic episode associated with premature birth, a more recent examination of her neuroanatomical profile has indicated the possibility that abnormalities within the hippocampus and structures closely connected to it occurred prenatally, in early fetal development. In addition to the previously reported hippocampal volume loss, abnormal development of the extended hippocampal system is also evident, including aplasia of the mammillary bodies, atrophy of the anterior thalamic nuclei bilaterally, hypogenesis of the fornices, and abnormal hippocampal shape and orientation (Rosenbaum et al., 2014b). These developmental abnormalities likely restrict hippocampal output, which may lead to greater impairment than expected given her relatively modest hippocampal volume decrease.

H.C.'s neuropsychological profile is well documented (Hurley et al., 2011; Rosenbaum et al., 2011; Table 1). Her IQ is in the average range and she has relatively intact semantic memory but impaired episodic and public event memory (Rosenbaum et al., 2011). She graduated from a mainstream high school and completed 2 years of postsecondary education.

H.C.'s performance was compared with that of 32 healthy control participants ( 24 female). The control participants were equivalent in age (mean, 23.28 years; $\mathrm{SD}=3.38, p_{\text {two-tailed }}=0.94$ ) and education (mean, 16.75 years, $\mathrm{SD}=2.42, p_{\text {two-tailed }}=0.27$ ). Due to technical difficulties, recognition data were not collected for three of the 32 control participants who participated in the study phase.

Apparatus, classification of fixations and transitions. Stimuli were presented on a 19 inch Dell M991 monitor (resolution $1024 \times 768$ ) from a distance of 24 inches. Monocular eye movements were recorded with a head-mounted EyeLink II eyetracker (sample rate, $500 \mathrm{~Hz}$; SR Research). Eye-movement calibration was performed at the beginning of the experiment, and drift correction $\left(>2^{\circ}\right)$, if needed, was performed immediately before the onset of each trial. Saccades were determined using the built-in EyeLink saccade-detector heuristic; acceleration and velocity thresholds were set to detect saccades $>0.5^{\circ}$ of visual angle. Blinks are defined as periods in which the saccade-detector signal was missing for $\geq 3$ samples
Table 1. Neuropsychological test scores for H.C.

\begin{tabular}{|c|c|}
\hline Test & Score \\
\hline \multicolumn{2}{|l|}{ General Intellectual Function } \\
\hline \multicolumn{2}{|l|}{ Wechsler Abbreviated Scale of Intelligence ${ }^{a}$} \\
\hline Verbal IQ (standard score) & 104 \\
\hline Performance IQ (standard score) & 106 \\
\hline Full Scale IQ (standard score) & 106 \\
\hline American National Adult Reading Test ${ }^{b}$ (standard score) & 101.28 (estimated full-scale IQ) \\
\hline \multicolumn{2}{|l|}{ Anterograde memory } \\
\hline \multicolumn{2}{|l|}{ Wechsler Memory Scale-IIII, ${ }^{a, c d}$} \\
\hline Logical Memory I—immediate recall (scaled score) & 4 \\
\hline Logical Memory II-delayed recall (scaled score) & 1 \\
\hline \multicolumn{2}{|l|}{ California Verbal Learning Test $\|^{e}$} \\
\hline Total trials 1-5 (T-score) & 38 \\
\hline Short-delay free recall (z-score) & -4 \\
\hline Long-delay free recall (z-score) & -3 \\
\hline Recognition & -2 \\
\hline \multicolumn{2}{|l|}{ Rey Osterrieth complex figure ${ }^{c}$} \\
\hline Immediate recall (T-score) & $<20$ \\
\hline Delayed recall (T-score) & $<20$ \\
\hline Delayed recognition一-total correct (T-score) & 22 \\
\hline \multicolumn{2}{|l|}{ Visuospatial function } \\
\hline $\begin{array}{l}\text { Wechsler Abbreviated Scale of Intelligence, Block Des- } \\
\text { ign }^{a} \text { (T-score) }\end{array}$ & 54 \\
\hline Rey Osterrieth Complex Figure — Copy (percentile) $)^{d, g}$ & $>16^{\text {th }}$ \\
\hline Judgment of Line Orientation ${ }^{h}$ (percentile) & $56^{\text {th }}$ \\
\hline Benton Facial Recognition ${ }^{h}$ (percentile) & $33-59^{\text {th }}$ \\
\hline \multicolumn{2}{|l|}{ Language production } \\
\hline Boston Naming Test (z-score) $)^{f}$ & 0.75 \\
\hline Semantic Fluency' (animals; percentile) & $>90^{\text {th }}$ \\
\hline $\begin{array}{l}\text { Wechsler Abbreviated Scale of Intelligence, Vocabulary } \\
\text { (T-score) }\end{array}$ & 55 \\
\hline \multicolumn{2}{|l|}{ Attention and executive function } \\
\hline \multicolumn{2}{|l|}{ Stroop $\mathrm{p}^{j, k}$} \\
\hline Word condition (z-score) & 3.65 \\
\hline Color condition (z-score) & -0.03 \\
\hline Interference condition (z-score) & -0.57 \\
\hline Word errors (z-score) & 0 \\
\hline Color errors (z-score) & -0.50 \\
\hline Interference errors (z-score) & -0.13 \\
\hline Word self-corrections (z-score) & -0.50 \\
\hline Color self-corrections (z-score) & -0.71 \\
\hline Interference self-corrections (z-score) & 1.44 \\
\hline \multicolumn{2}{|l|}{ Trail Making Test $^{f}$} \\
\hline Part A (z-score) & 0.69 \\
\hline Part B (z-score) & -0.23 \\
\hline Wisconsin Card Sorting Task—Categories (T-score) ${ }^{\prime}$ & 57 \\
\hline $\begin{array}{l}\text { Wechsler Abbreviated Scale of Intelligence, Similarities } \\
\text { (T-score) }\end{array}$ & 50 \\
\hline $\begin{array}{l}\text { Wechsler Abbreviated Scale of Intelligence—Matrix } \\
\text { Reasoning (T-score) }\end{array}$ & 55 \\
\hline \multicolumn{2}{|l|}{ Processing speed } \\
\hline $\begin{array}{l}\text { Wechsler Adult Intelligence Scale-1II }{ }^{m} \text {, Digit Symbol } \\
\text { (scaled score) }\end{array}$ & 13 \\
\hline $\begin{array}{l}\text { Wechsler Adult Intelligence Scale-III, Symbol Search } \\
\text { (scaled score) }\end{array}$ & 14 \\
\hline
\end{tabular}

\section{a Wechsler, 1999.}

${ }^{b}$ Grober and Sliwinski, 1991.

'Wechsler, 1997.

${ }^{d} 17.8$ years old at time of testing.

eDelis et al., 1987.

fSpreen and Strauss, 1998.

${ }^{9}$ Meyers and Meyers, 1996.

hBenton, 1994.

iBenton et al., 1994.

jStroop, 1935.

${ }^{k}$ In-house unpublished normative data.

'Heaton et al., 1993.

${ }^{m}$ Wechsler, 1997. 


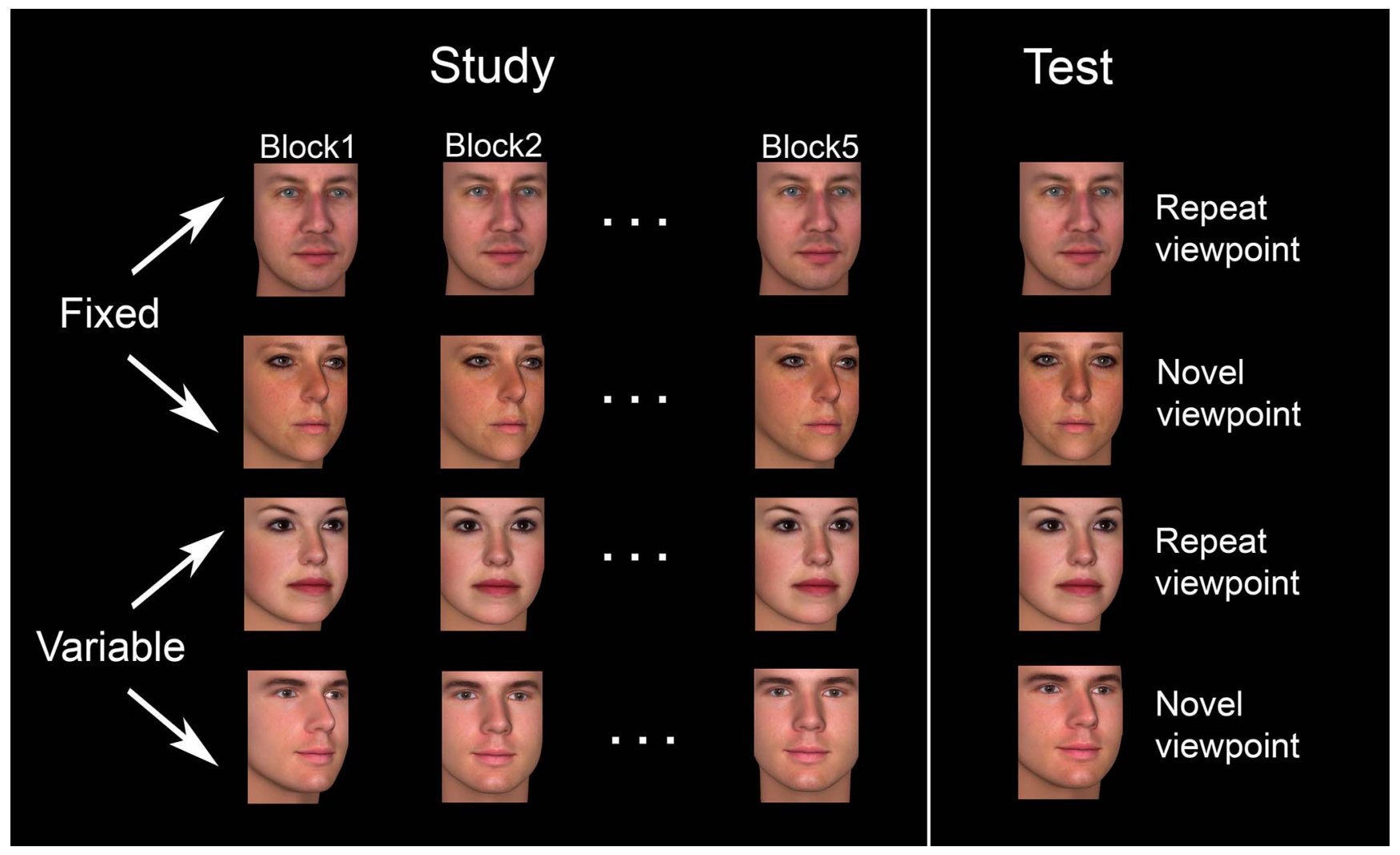

Figure 1. Task design. Left, The study phase consisted of five study blocks in which 80 faces were presented in each block. Each face was displayed for $4 \mathrm{~s}$ and participants made a gender judgment. Face viewpoint was either held constant across study blocks (fixed condition) or a different viewpoint was shown in each study block (variable condition). Right, Surprise memory test consisted of 80 previously studied faces and 80 nonstudied faces. Among the previously studied faces, half were shown from a repeated viewpoint and half were shown from a novel viewpoint. For faces studied from variable viewpoints, the repeated viewpoint was the same as the viewpoint used in the fifth study block. Participants made a memory judgment using a five-point recognition confidence scale (1, sure new; 5 , sure old).

in a sequence. Fixations are defined as the samples remaining after the categorization of saccades and blinks.

To further understand how participants directed their viewing to the faces during the study phase, the number of gaze transitions was calculated (Firestone et al., 2007; Hannula et al., 2010). This analysis quantifies the number of times a participant shifted his/her gaze among the distinct regions of the face. Transitions were calculated in the following way: a transition occurred when an eye movement was made into or out of a particular facial feature (for description of the face-feature area of interest definition, see Stimuli and predefined areas of interest section below). This procedure was calculated to provide (1) the overall number of transitions per face, and (2) the number of transitions for each feature, separately. Note that in the latter analysis, the sum of the number of transitions for each feature may be greater than in the former analysis, given that an eye movement that originates in one facial feature and terminates in another will be included in the transition count for each feature separately. Finally, for each subject, the average number of transitions was divided by the average number of fixations to evaluate the rate of change among facial features relative to the total number of times a person gazed upon a particular location.

Stimuli and predefined areas of interest. Realistic, three-dimensional face/head models ( 80 female, 80 male) were created using FaceGen Modeler's Generate function (Singular Inversions). Computer-generated faces were used as experimental stimuli to enable the precise manipulation of viewing angle and to make contact with previous literature on face memory and amnesia. All faces were posed with a neutral expression or with a slight smile. A range of skin tones, eye colors, facial shapes (e.g., cheekbones, jawline), and feature shapes/sizes were used across the set of faces. Special skin textures, available with the FaceGen Modeler software, were used to increase realism.

Each face model $(n=160)$ was captured in six different viewpoints: $0^{\circ}$ (or front view), $5^{\circ}, 10^{\circ}, 15^{\circ}, 20^{\circ}$, or $25^{\circ}$ turned to the viewer's right, for a total of 960 images. Face images were cropped above the eyebrows, below the chin, and on the sides so that the top of the head, most of the neck, and the ears were not shown. The crop box used for each face viewpoint was identical; all images measured 316 (width) $\times 405$ (height) pixels. For all viewpoints, the top of the crop box was anchored to a horizontal position located $\sim 15$ pixels above the eyebrows.

To ascertain that the computer-generated faces were distinguishable as male or female, even without the presence of hair, gender ratings on each face were collected by a separate group of participants $(n=12)$. These participants were able to accurately categorize both male (mean, 0.99; $\mathrm{SD}=0.01)$ and female (mean, $0.98 ; \mathrm{SD}=0.02)$ faces.

Regions of interest (ROIs) were manually defined, a priori, for each face and for each viewpoint, separately. Face-feature ROIs were defined to for the eyes, nose, and mouth. Each ROI was rectangular in shape, and the size was held constant across all faces and viewpoints, and the placement of these ROIs was anchored to the location of each feature for a specific face. A single ROI was used for both eyes; it was placed inferior to the eyebrows and the size was 290 (width) $\times 50$ (height) pixels. The nose ROI was 120 (width) $\times 100$ pixels and care was taken to ensure that the width of the nose accommodated each face. The nose ROI was placed inferior to the eye ROI (which included the nasion). Thus, the nose ROI included the lower nasal bridge, nostrils, columella, and alar sidewalls. The size of the mouth ROI was 180 (width) $\times 80$ (height) pixels and contained the lower part of the philtrum in addition to the upper and lower lip.

Experimental design. The experimental testing session consisted of a study phase, during which faces were incidentally encoded and participants' eye movements were recorded, followed by a surprise recognition memory test phase. Eighty faces (half female) were repeated five times across the five study blocks (once per block). Each face was presented for $4 \mathrm{~s}$ and participants were asked to judge whether the face was male or female. Participants indicated their responses using a hand-held button box and response times (RTs) were recorded. Forty faces were presented 


\section{A Gender judgment accuracy}

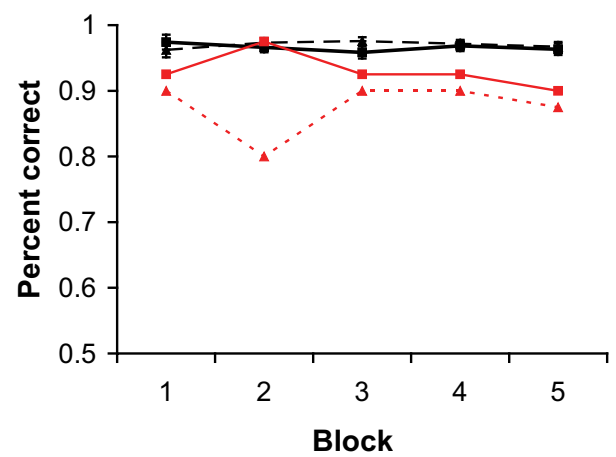

B Response Time

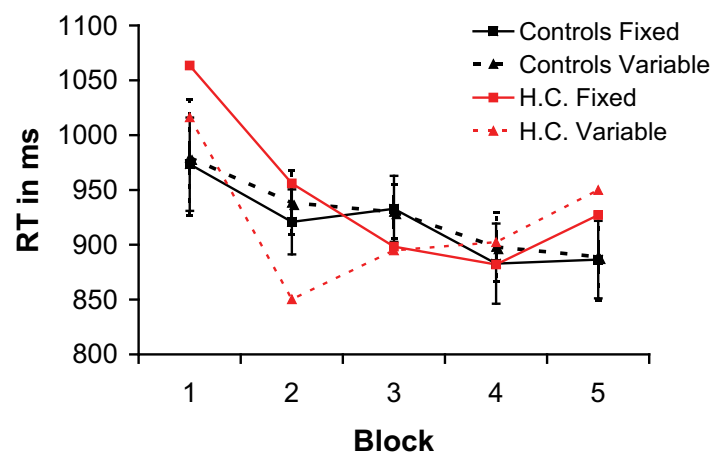

Figure 2. Behavioral results from the study phase. $A$, Accuracy on the gender judgment is plotted for controls (black) and H.C. (red). Solid lines correspond to the faces shown in the fixed-viewpoint condition and dashed lines correspond to faces shown in the variable-viewpoint condition. Controls perform near ceiling for both fixed and variable faces. H.C.'s accuracy was similar to that of controls for faces presented in the fixed-viewpoint condition, and was less accurate than controls for faces presented in the variable-viewpoint condition, due to the large number of errors ( 8 of the 40 variable-viewpoint faces) made by H.C. during the second study block. B, RT on correct trials of the gender judgment task. RT decreases from the first to fifth study blocks were not significantly different between H.C. and controls for either the variable or the fixed condition. Error bars depict $95 \% \mathrm{Cl}$ of the control mean.

in the identical viewpoint (fixed condition; Fig. 1, top left) across the five study blocks and 40 faces were shown in five different viewpoints (variable condition; Fig. 1, bottom left) across repetitions. For example, if a face was shown in the variable condition, a participant might see it from the following viewpoints: block $1,5^{\circ}$ rotated; block $2,20^{\circ}$ rotated; block 3 , $25^{\circ}$ rotated; block $4,10^{\circ}$ rotated; block $5,0^{\circ}$ rotated (front view). Faces were assigned to the fixed and variable conditions as counterbalanced across participants. The final study block was followed by a $5 \mathrm{~min}$ break, and then the recognition memory test was administered. During the recognition test, 160 faces were shown (80 previously studied and 80 nonstudied). Each face was presented for $3 \mathrm{~s}$ and participants judged whether the face had been previously presented in the study phase. Participants were instructed that some of the faces would be shown from different viewpoints than those that had been previously studied and to make their memory judgments based on face identity rather than viewpoint. Memory judgments were reported verbally to the experimenter using a five-point confidence scale ( 1 , sure new; 2 , probably new; 3 , guess; 4 , probably old; 5 , sure old). Of the 40 faces that were presented in the fixed condition during the study phase, half were tested in the previously studied viewpoint (fixed-repeat viewpoint) and half were shown in a novel viewpoint (fixed-novel viewpoint). Novel viewpoints were selected so that they were $15^{\circ}$ away from the studied viewpoint (e.g., if the studied viewpoint was $20^{\circ}$, the tested viewpoint was $5^{\circ}$ ). Of the 40 faces presented in the variable condition during the study phase, 20 faces were tested in the same view that was presented in the fifth study block (variable-repeat viewpoint) and 20 faces were tested in a novel viewpoint (variable-novel viewpoint). As in the fixed-novel viewpoint condition, the viewpoint of the test faces in the variable-novel viewpoint condition were $15^{\circ}$ away from the viewpoint shown in the final study block. Repeat-viewpoint and novel-viewpoint test probes were counterbalanced across participants as were studied versus nonstudied faces.

Statistics. Repeated-measures ANOVA in SPSS (IBM, v. 20) was used to assess differences in performance for within-subject conditions (e.g., variable-viewpoint vs fixed-viewpoint conditions) within the control group. Modified $t$ tests, which were developed for assessing differences between single cases and a sample population (Crawford and Howell, 1998; Crawford et al., 2010), were used to assess statistical significance between H.C. and control participants. One-tailed tests were used when a specific a priori hypothesis predicted a difference between H.C. and controls as indicated below. The $\alpha$ level was set to 0.05 to establish significance for all tests. Effect sizes are reported for both ANOVA and modified $t$ test results using partial $\eta$ squared $\left(\eta_{\mathrm{p}}^{2}\right)$ and $z_{\mathrm{CC}} \pm 95 \%$ confidence interval (CI), respectively. To test for within-subject effects for H.C. (e.g., percentage of fixations to eyes for fixed vs variable views) bootstrapping was performed using the adjusted bootstrap percentile (BCa) method in R ( $\mathrm{R}$ Studio 0.98 .1049 ) with the package boot. This function was used to produce 95\% CI (Efron, 1987; Davison and Hinkley, 1997; Canty and Ripley, 2014).

\section{Results}

Study phase: behavioral results

H.C. has not exhibited obvious visual-perceptual difficulties and has previously demonstrated the ability to discriminate between highly similar faces when they are presented simultaneously (Rose et al., 2012). Thus, no performance differences between H.C. and controls were expected during the incidental encoding task (male-female gender judgments) during the study phase. While H.C. performed as accurately as controls on the gender judgment task for faces shown in the fixed-viewpoint condition (Controls: mean, 0.98; SD =0.03; H.C.: mean, $0.94, p_{\text {two-tailed }}=$ 0.13 ; Fig. $2 A$, solid lines), she performed significantly worse than controls on the gender judgment for faces presented in variable viewpoints across study blocks [Controls: mean, 0.98 ; $\mathrm{SD}=0.03$; H.C.: mean, $0.88, p_{\text {two-tailed }}=0.004, z \pm 95 \% \mathrm{CI}=-3.16(-4.00$, $-2.30)$; Fig. $2 A$, dashed lines]. Also, while control participants performed close to ceiling (between 97 and 98\% correct) on the gender judgment task across the five study blocks, H.C.'s performance decreased slightly across blocks (from 95 to $90 \%$ correct on fixed-view trials and from 90 to $87.5 \%$ correct on variableview trials). This performance decrement was not significantly different from that of controls (fixed-view faces, $p_{\text {two-tailed }}=0.14$; variable-view faces, $p_{\text {two-tailed }}=0.78$ ), but may indicate a subtle buildup of interference, which adversely affected performance. Computational models have indicated a critical role for the hippocampus, especially the dentate gyrus, in minimizing interference (Marr, 1971; O’Reilly and McClelland, 1994). We note that ceiling effects on the gender judgment performance may have obscured significant group differences.

As expected, for both H.C. and controls, RT decreased across the five study blocks for both fixed-viewpoint and variableviewpoint faces. The mean RT decrease for control participants from block 1 to block 5 was $86.91 \mathrm{~ms}(\mathrm{SD}=185.45)$ for faces presented in the fixed condition and the mean decrease was $90.43 \mathrm{~ms}$ $(\mathrm{SD}=218.27)$ for faces presented in the variable condition (Fig. 2B). The mean RT decrease from block 1 to block 5 for H.C. was 136.42 $\mathrm{ms}$ for the fixed condition and $66.32 \mathrm{~ms}$ for the variable condition. The RT decrease exhibited by H.C. did not significantly differ from that of controls in either the fixed ( $p_{\text {two-tailed }}=$ 

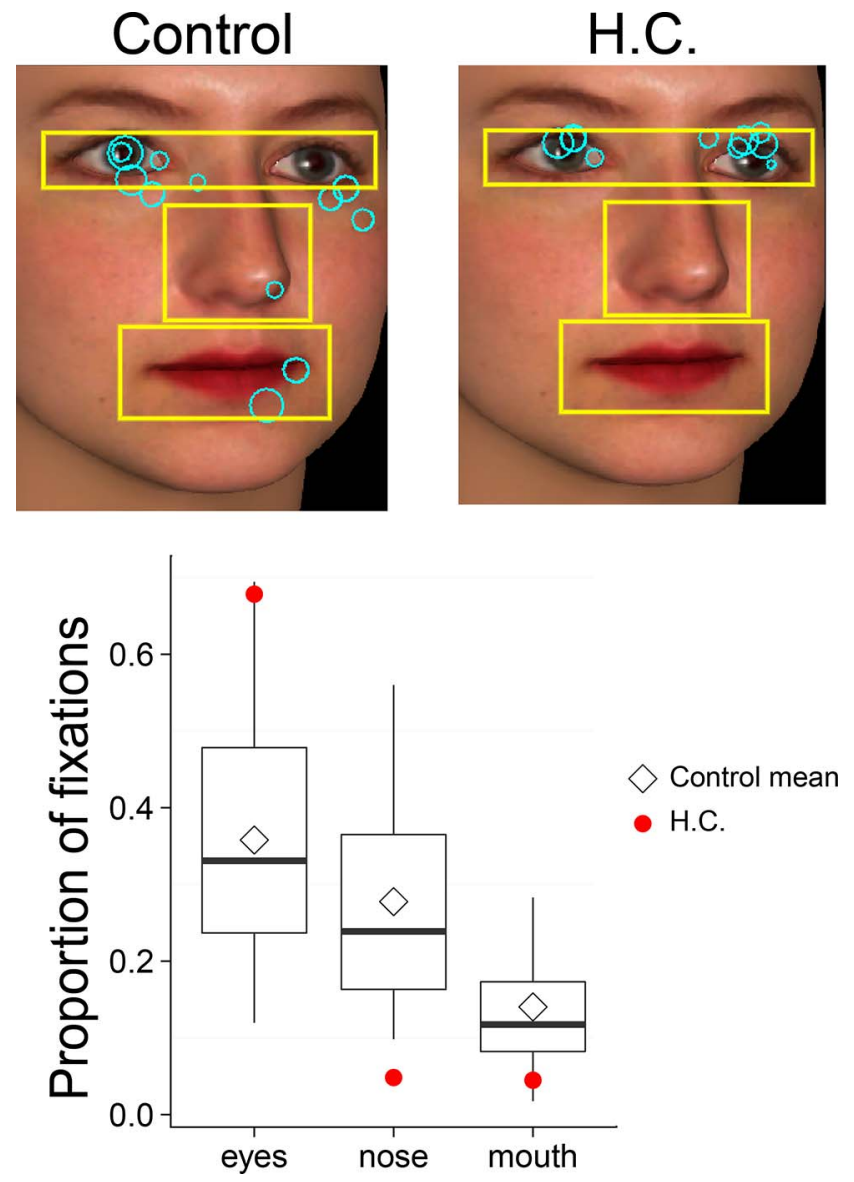

Figure 3. Top, Example of eye fixations (teal circles) made by a representative control (left) and by H.C. (right) during the study phase. Yellow boxes depict the ROls (eyes, nose, mouth) used for data analysis and were not displayed on the computer screen during the experiment. Bottom, Proportion of fixations directed to the individual facial features (collapsed across study blocks) for H.C. (red circle) and control participants (black box plot). H.C. directed significantly more viewing to the eyes than the control group. Box plot whiskers depict the $95 \% \mathrm{Cl}$ of the control group.

$0.79)$ or variable $\left(p_{\text {two-tailed }}=0.91\right)$ conditions. In addition, the difference between fixed and variable RT decreases $\left[\left(\right.\right.$ Fixed $_{\text {block } 1}$ RT - Fixed $_{\text {block } 5}$ RT $)-\left(\right.$ Variable $_{\text {block } 1}$ RT Variable $_{\text {block5 }}$ RT)] was not significantly different between H.C. and controls $\left(p_{\text {two-tailed }}=0.592\right)$.

\section{Study phase: eye-movement results}

First, a potential baseline viewing difference, as indexed by the total number of fixations to the face during the entire $4 \mathrm{~s}$ viewing period, between H.C. and controls was evaluated. On average, controls made 10.92 ( $\mathrm{SD}=2.24$ ) fixations to the entire face during the initial study block and H.C. made 11.91 fixations. This difference was not statistically significant $\left(p_{\text {two-tailed }}=0.66\right)$.

The proportion of fixations to the specific facial features was also investigated (Fig. 3). Collapsing the data across block and viewpoint condition factors, control participants directed 36, 28, and $14 \%$ of their fixations to the eyes, nose, and mouth, respectively, and H.C. directed $68 \%$ of her fixations to the eye region and between 4 and $5 \%$ of her fixations to the nose and mouth. The proportion of fixations directed to the eye region between controls and H.C. was statistically significant $\left(p_{\text {two-tailed }}=0.05\right.$; $z \pm 95 \% \mathrm{CI}=2.104(1.47 ; 2.73)$, and viewing the nose and the mouth did not differ between H.C. and controls ( $p_{\text {two-tailed }}=$ 0.12 for the nose and $p_{\text {two-tailed }}=0.27$ for the mouth). Within the control group, there was a significant main effect of face feature $\left(F_{(2,62)}=15.81, p<0.001, \eta_{\mathrm{p}}^{2}=0.34\right)$ and while the main effect of repetition was nonsignificant $\left(F_{(4,124)}=0.76, p=0.55\right)$ a significant repetition-by-feature interaction $\left(F_{(8,248)}=4.97, p<\right.$ $\left.0.001, \eta_{\mathrm{p}}^{2}=0.14\right)$ was found. This interaction was driven by the fact that the proportion of fixations directed to the eyes increased across blocks (from 31 to $38 \%$ ) whereas the proportion of fixations to the other features either stayed the same $(28 \%$ for the nose) or decreased (17 to $12 \%$ for the mouth) across blocks. In controls, there was no significant difference in viewing to individual features as a function of condition (fixed vs variable; $\left.F_{(1,31)}=0.18, p=0.67\right)$ and no other interaction was significant. H.C. increased her viewing of the eyes upon repetition from the first to the fourth block (the proportion of fixations to the eyes increased across blocks from 68 to $77 \%$ ) and then dropped to $58 \%$ for the final study block. She devoted fewer fixations to the nose (from 6 to $4 \%$ ) and the mouth (from 8 to $3 \%$ ) across the five study repetitions. The distribution of H.C.'s fixations to the facial features (collapsed across blocks) did not differ significantly between the fixed and variable conditions. This was tested by using a bootstrapping procedure to generate $95 \%$ CIs of the mean proportion of viewing for the eyes, nose, and mouth for fixed and variable conditions separately. The $95 \%$ CIs were overlapping for the eyes (fixed, 95\% CI: 0.63, 0.70; variable, 95\% CI: 0.64, 0.70), nose (fixed, 95\% CI: 0.04, 0.06; variable, 95\% CI: 0.04, 0.06), and mouth (fixed, 95\% CI: 0.03, 0.05; variable, 95\% CI: 0.04, 0.06).

The number of facial feature transitions (both into and out of the feature ROIs) was calculated for each participant to test whether H.C. made fewer transitions among the different facial features. The overall number of transitions (regardless of the particular face feature) was not significantly different between H.C. and controls (H.C.: mean, 4.85; controls: mean, 5.92; SD = 1.26; $\left.p_{\text {one-tailed }}=0.21\right)$. However, the transition-to-fixation ratio was significantly lower in H.C. compared with controls [H.C.: mean, 0.37 ; controls: mean, $0.51 ; \mathrm{SD}=0.08 ; p_{\text {one-tailed }}=0.05, z \pm 95 \%$ $\mathrm{CI}=-1.71(-2.25,-1.15)]$. Finally, the number of transitions was computed for each facial feature, separately. The number of transitions into/out of the nose was significantly lower for H.C. compared with controls [H.C.: mean, 1.85; controls: mean, 3.53, $\mathrm{SD}=0.92 ; p_{\text {one-tailed }}=0.04, z \pm 95 \% \mathrm{CI}=-1.83(-2.39$, -1.25 )], but did not differ for the eyes (H.C.: mean, 3.15; controls: mean, $3.76, \mathrm{SD}=0.96 ; p_{\text {one-tailed }}=0.27$ ) or mouth (H.C.: mean, 0.77 ; controls: mean, $2.00, \mathrm{SD}=1.13$; $p_{\text {one-tailed }}=0.15$ ). Similarly, the transition-to-fixation ratio differed significantly for the nose (H.C.: mean, 0.15; controls: mean, 0.31 , SD = $0.06 ; p_{\text {one-tailed }}=0.007, z \pm 95 \% \mathrm{CI}=-2.67(-3.41,-1.92)$ but not for the eyes (H.C.: mean, 0.29; controls: mean, 0.27; $\mathrm{SD}=0.07 ; p_{\text {one-tailed }}=0.39$ ) or mouth (H.C.: mean, 0.05; controls: mean, $0.17, \mathrm{SD}=0.10 ; p_{\text {one-tailed }}=0.12$ ).

\section{Test phase: recognition results}

Recognition memory performance was assessed by computing corrected recognition scores for each participant for each of the four test probe conditions: fixed-repeat viewpoint, fixed-novel viewpoint, variable-repeat viewpoint, and variable-novel viewpoint (Fig. 1). Recognition responses were classified in the following way: "sure old" and "probably old" responses (i.e., when participants responded " 5 " and " 4 ") to studied faces were classified as "hits"; "sure old" and "probably old" responses to unstudied faces were classified as false alarms; guesses (i.e., " 3 " responses) were seldom used (Table 2) and were not included in this analysis. Corrected recognition was calculated for each participant by subtracting the false-alarm rate from the hit rate. In 
Table 2. Recognition memory confidence ratings for H.C. and controls

\begin{tabular}{|c|c|c|c|c|c|}
\hline \multirow[b]{2}{*}{ Group } & \multicolumn{5}{|c|}{ Confidence rating } \\
\hline & Sure new & Unsure new & Guess & Unsure old & Sure old \\
\hline \multicolumn{6}{|l|}{ Controls } \\
\hline Fixed-repeat & 0.07 & 0.09 & 0.07 & 0.19 & 0.58 \\
\hline Fixed-novel & 0.13 & 0.15 & 0.09 & 0.22 & 0.41 \\
\hline Variable-repeat & 0.09 & 0.10 & 0.09 & 0.21 & 0.51 \\
\hline Variable-novel & 0.11 & 0.12 & 0.11 & 0.22 & 0.44 \\
\hline Unstudied faces & 0.39 & 0.24 & 0.11 & 0.14 & 0.12 \\
\hline \multicolumn{6}{|l|}{ H.C. } \\
\hline Fixed-repeat & 0.10 & 0.10 & 0.00 & 0.20 & 0.60 \\
\hline Fixed-novel & 0.10 & 0.20 & 0.00 & 0.20 & 0.50 \\
\hline Variable-repeat & 0.10 & 0.35 & 0.00 & 0.30 & 0.25 \\
\hline Variable-novel & 0.10 & 0.40 & 0.00 & 0.25 & 0.25 \\
\hline Unstudied faces & 0.41 & 0.18 & 0.01 & 0.16 & 0.24 \\
\hline
\end{tabular}

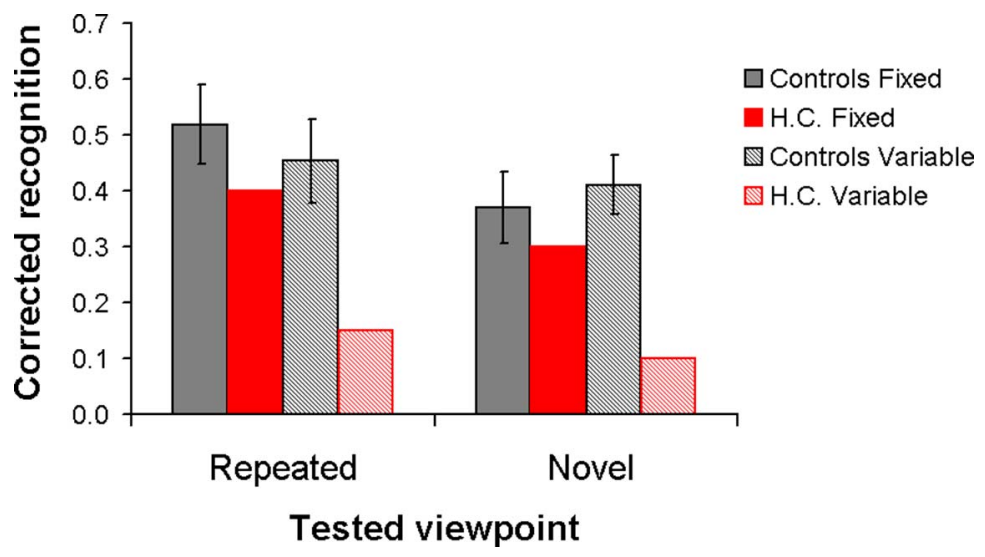

Figure 4. Recognition memory performance. Corrected recognition (hit rate minus false alarm rate) is plotted separately by study condition (fixed vs variable) and test viewpoint (repeated vs novel). Control participants (dark bars) were significantly more accurate at recognizing test probes that were shown in a repeated viewpoint. Furthermore, the performance benefit for repeatedviewpoint test probes was greater for faces studied from the same (fixed) viewpoint compared with those studied from variable viewpoints. H.C.'s accuracy (red bars) was similar to that of controls for faces studied in the same viewpoint across blocks (fixedrepeat and fixed-novel), and worse than controls for faces studied in the differing viewpoints across blocks (variable-repeat and variable-novel). Error bars reflect the $95 \% \mathrm{Cl}$ of the control group mean.

controls, there was a main effect of test-probe type $\left(F_{(1,28)}=\right.$ $\left.14.23, p=0.001, \eta_{\mathrm{p}}^{2}=0.34\right)$; repeated-viewpoint faces were endorsed as "old" more often than faces tested in a novel viewpoint (Fig. 4). There was no main effect of study viewpoint condition (fixed vs variable; $F_{(1,28)}=0.98, p=0.33, \eta_{\mathrm{p}}^{2}=0.03$ ); however, a significant interaction between the study viewpoint condition (fixed vs variable) and test-probe type (repeated vs novel viewpoint) was observed $\left(F_{(1,28)}=10.93, p=0.003, \eta_{\mathrm{p}}^{2}=0.28\right)$. This interaction resulted from a larger recognition advantage for repeated viewpoints for faces studied in the fixed condition compared with those studied in the variable condition. That is, recognition accuracy was higher for faces studied in the fixed condition and subsequently tested in the same view than when tested in a novel viewpoint (corrected recognition for same viewpoint: mean, 0.51 ; novel viewpoint: mean, 0.37 ); however, this same viewpoint advantage was not as pronounced for faces studied in the variable condition (corrected recognition for same viewpoint: mean, 0.45 ; novel viewpoint: mean, 0.41 ). These results converge with previous reports highlighting the viewpoint-dependent nature of memory for faces (Bruce, 1982; Longmore et al., 2008).

Like controls, H.C.'s explicit recognition performance was superior for faces tested in a repeated viewpoint compared with faces tested from a novel viewpoint (Fig. 4, red bars). However, her memory performance for faces studied from variable view- points across blocks (corrected recognition: mean, 0.125) was significantly less accurate than that of controls (mean, 0.43 ; $\mathrm{SD}=$ $0.15, p_{\text {one-tailed }}=0.03, z \pm 95 \% \mathrm{CI}=-2.033(-2.67,-1.38)$. Her memory for faces studied from the same viewpoint across blocks (corrected recognition, 0.35) did not differ from that of controls (mean, $0.44 ; \mathrm{SD}=0.16 ; p_{\text {one-tailed }}=0.29$ ). Using the standard established by Crawford et al. (2003) for a dissociation in performance among two tasks, H.C.'s pattern of performance on the two study conditions (fixed and variable) fulfils the criteria for a classical dissociation. That is, she falls within the range of her controls for fixedview faces and her performance is significantly impaired for variableview faces.

Paired comparisons between H.C. and controls for each of the four test-probe conditions (fixed-repeat viewpoint, fixed-novel viewpoint, variable-repeat viewpoint, variable-novel viewpoint) were also tested. On the variable-view faces, H.C.'s recognition performance was marginally less accurate than that of the controls for the variable-repeat viewpoint condition $\left[p_{\text {one-tailed }}=0.08, z \pm 95 \% \mathrm{CI}=-1.50\right.$ $(-2.02,-0.96)]$ and significantly less accurate on the variable-novel viewpoint condition $\left[p_{\text {one-tailed }}=0.02, z \pm 95 \%\right.$ $\mathrm{CI}=-2.21(-2.89,-1.53)]$. For the faces studied from a fixed viewpoint, H.C.'s performance was not significantly different from that of controls in the fixed-repeat viewpoint condition ( $p_{\text {one-tailed }}=0.27$ ) or in the fixed-novel viewpoint condition $\left(p_{\text {one-tailed }}=0.34\right)$.

\section{Discussion}

Multiple accounts of MTL function posit that the hippocampus is critical for memory regarding the relations among items, whereas regions within the MTL cortex can support memory for single items (Cohen and Eichenbaum, 1993; Eichenbaum and Cohen, 2001; Davachi, 2006; Mayes et al., 2007; Montaldi and Mayes, 2010). However, other theories posit that the hippocampus and MTL cortex are each critically involved in item memory (Squire et al., 2007). Here, we show that a more nuanced interpretation is necessary when considering the role of the hippocampus and MTL cortex in item memory. Specifically, the current findings suggest that the hippocampus supports the flexible integration of item representations across different viewpoints, whereas extrahippocampal regions, including areas of MTL cortex, are sufficient for memory formation when the viewpoint of the items does not vary across repetitions, and may even support recognition across viewpoints after sufficient study repetitions. Moreover, hippocampal compromise affects the nature of on-line processing during item encoding likely to the detriment of subsequent memory for those items.

Face recognition has been studied extensively in amnesia. Several early investigations of face memory in amnesics of mixed etiology (e.g., temporal lobectomy, Korsakoff's syndrome, hypoxia) reported impairments in both long-delay and short-delay face recognition (Milner, 1968; Warrington and Taylor, 1973). Later reports found long-delay face memory to be relatively intact in amnesics with damage limited to the hippocampus (Reed and Squire, 1997; Carlesimo et al., 2001; Mayes et al., 2002; Turriziani et al., 2004; Cipolotti et al., 2006; Bird et al., 2007, 2008; Taylor et 
al., 2007; Bird and Burgess, 2008), leading some researchers to conclude that face memory is "special" and relies on extrahippocampal structures. Both adult-onset and developmental amnesic cases with selective hippocampal damage showed greater memory impairments for scenes, buildings, and words compared with faces. The current results converge with and extend this literature. H.C.'s recognition of faces studied consistently from the same viewpoint was similar to that of controls. This suggests that areas outside of the hippocampus are sufficient to support memory under testing conditions in which items retain the same format across repetitions. However, her relatively poor recognition of faces studied from variable views lends insight into the underlying computations that require the hippocampus to support item memory. Namely, the relational binding requirements inherent to the task determine the extent of hippocampal system involvement in item memory, and the extent of the impairment in amnesia.

In addition to H.C.'s impaired recognition judgments, the differences in gender judgments in her on-line viewing behavior suggest a role for hippocampal involvement during item encoding. H.C.'s gender judgments were less accurate than that of controls and decreased across blocks. Significant differences in the distribution of fixations and rate of transitions among facial features were observed between H.C. and controls during the study phase. H.C. primarily restricted her viewing to the eye region, and her eye movements did not transition into the nose region as often as those of controls. H.C.'s compromised hippocampal system and corresponding binding deficits have consequences for the way she processes complex items, such as faces, biasing her to direct encoding toward a single feature or "item" rather than on the relations among the "items." This may be an intentional strategy used by H.C., but again, this strategy shift would presumably occur in response to a binding deficit brought on by reduced hippocampal function. Nevertheless, H.C.'s subsequent memory performance cannot be solely attributed to the amount of information encoded relative to her controls. If the amount of information encoded were the critical dimension in determining memory performance, she should have demonstrated impaired performance on all memory probe types; rather, she shows a specific recognition deficit for faces that were studied from variable viewpoints. Together, this evidence suggests that representations formed by the hippocampus play a role in guiding ongoing perceptual processing, consistent with recent proposals regarding the wider reach of hippocampal function in cognition (Lee et al., 2012; Olsen et al., 2012).

H.C.'s intact recognition of faces in the fixed-novel viewpoint condition has implications for the specific types of representations mediated by the hippocampus and MTL cortex. We propose that study repetitions gradually "tune" the MTL item memory representations; and tuning occurs more readily when the viewpoint is fixed across study repetitions than when it changes. The tuning process is thought to result in a "sharpening" or "pruning" of the cortical representation until it contains only the most relevant features of the item (Desimone, 1996; Wiggs and Martin, 1998; Grill-Spector et al., 2006). This sharpened representation may even be sufficient to support recognition of faces that are presented from a different viewpoint at test. However, these sharpened representations do not enable recognition through flexible knowledge of the spatial relations among facial features (as would otherwise be afforded rapidly by the hippocampus); instead, they enable recognition either through (1) identification of the most relevant facial features (feature-based processing) or (2) the extrapolation/generalization of different viewpoint representations based on the stored representation (Bülthoff and Edelman, 1992).

Recognition can be affected by test-related factors; in particular, test format and lure type may determine whether impaired or intact performance is observed in amnesic individuals. For example, Taylor et al. (2007) described hippocampal amnesics who showed intact face recognition even for novel-view faces, despite the fact that they only studied the face once, precluding a "slow-learning" response as described above. Because their study used a forced-choice test format, participants could have achieved intact performance through the assessment of relative stimulus novelty among the studied and novel lure items, which were simultaneously presented. Intact performance as reported by Taylor and colleagues and as observed on the fixed-view condition of the current study may have occurred for different reasons: novelty detection versus a "slow-learning" generalization or feature-based recognition.

In addition to test format, face-recognition performance in amnesia may vary depending on the type of memory lure used during the test phase. For example, recognition following brief $(8$ s) delays was impaired in H.C. when the lures were composed of "morphed" faces and therefore differed from the studied faces in subtle ways instead of comprising an entirely new face identity (Ezzyat and Olson, 2008; Rose et al., 2012). This experimental manipulation reduces the ability to use novelty detection, and likely required hippocampal memory representations to support detailed knowledge of spatial relations among facial features. By contrast, Race et al. (2013) reported that short-delay recognition performance was intact in hippocampal amnesics when novel faces were used as lures in the test phase (see also, Shrager et al., 2008). Successful performance in the Race et al. (2013) study could occur through detection of a previously viewed feature, the maintenance of an inflexible configural face representation, or novelty detection. In summary, the extent to which the hippocampus supports item memory may depend on a variety of factors across study and test phases.

H.C. performs normally on tests of processing speed; tests of visual attention (Table 1; Hurley et al., 2011); tests that require inspection of faces, such as standard theory of mind tests (Rabin et al., 2012); and tests that involve imagining the experiences of unfamiliar others' depicted in real-life photos (Rabin et al., 2013). H.C. also performs within the normal range on the Benton Facial Recognition Test (Benton et al., 1994), which requires matching face identity among different faces presented simultaneously across different viewpoints; however, that task can be performed with a feature-matching strategy (Duchaine and Weidenfeld, 2003; Duchaine and Nakayama, 2004). Therefore, we attribute differences in H.C.'s viewing behavior to an inability to form integrated, flexible memory representations for faces studied from variable views across repetitions. Together with evidence implicating the hippocampus in the binding of relations that are nonspatial in nature (Rickard et al., 2006; Konkel et al., 2008; Moses et al., 2008), the impairments observed in H.C. likely reflect a general relational binding deficit as opposed to a specific deficit in processing spatial information present in faces.

The recognition and eye-movement data from H.C. provides unique insight into the broad impact of hippocampal compromise on cognition, adding to the body of literature in which single-case studies have informed our understanding of brainbehavior relationships (Rosenbaum et al., 2014a). As with any case study, careful consideration of issues that are inherent to single-case studies must be heeded and converging evidence from additional hippocampal amnesics must be obtained for the for- 
mation of definitive conclusions. It is also important to note that H.C. has developmental, as opposed to adult-onset, amnesia, which may produce unique patterns of results.

Nonetheless, these results suggest that the hippocampus is necessary for item memory when performance critically requires across-repetition binding of physically modified items, and/or the formation of flexible associations among the elements within an item. These findings speak to the long-standing conflicting views regarding whether the hippocampus is critical for item memory-providing intriguing new evidence for the view that the hippocampus is necessary for item memory specifically when relational representations are necessary to support performance.

\section{References}

Aly M, Knight RT, Yonelinas AP (2010) Faces are special but not too special: spared face recognition in amnesia is based on familiarity. Neuropsychologia 48:3941-3948. CrossRef Medline

Benton AL (1994) Contributions to neuropsychological assessment: a clinical manual. New York: Oxford UP.

Benton AL, Hamsher KD, Sivan AB (1994) Multilingual aphasia examination: manual of instruction. Iowa City: AJA Associates.

Bird CM, Burgess N (2008) Report: the hippocampus supports recognition memory for familiar words but not unfamiliar faces. Curr Biol 18:19321936. CrossRef Medline

Bird CM, Shallice T, Cipolotti L (2007) Fractionation of memory in medial temporal lobe amnesia. Neuropsychologia 45:1160-1171. CrossRef Medline

Bird CM, Vargha-Khadem F, Burgess N (2008) Impaired memory for scenes but not faces in developmental hippocampal amnesia: a case study. Neuropsychologia 46:1050-1059. CrossRef Medline

Brown MW, Aggleton JP (2001) Recognition memory: what are the roles of the perirhinal cortex and hippocampus? Nat Rev Neurosci 2:51-61. CrossRef Medline

Bruce V (1982) Changing faces: visual and nonvisual coding processes in face recognition. Br J Psychol 73:105-116. CrossRef Medline

Bülthoff H, Edelman S (1992) Psychophysical support for a twodimensional view interpolation theory of object recognition. Proc Natl Acad Sci U S A 89:60-64. CrossRef Medline

Bussey TJ, Saksida LM (2002) The organization of visual object representations: a connectionist model of effects of lesions in perirhinal cortex. Eur J Neurosci 15:355-364. CrossRef Medline

Canty A, Ripley BD (2014) boot: Bootstrap R (S-Plus) functions. R package version 1.3-13 (1-117).

Carlesimo GA, Fadda L, Turriziani P, Tomaiuolo F, Caltagirone C, Neurologica C, Roma U (2001) Selective sparing of face learning in a global amnesic patient. J Neurol Nuerosurg Psychiatry 71:340-346. CrossRef Medline

Cipolotti L, Bird C, Good T, Macmanus D, Rudge P, Shallice T (2006) Recollection and familiarity in dense hippocampal amnesia: a case study. Neuropsychologia 44:489-506. CrossRef Medline

Cohen NJ, Eichenbaum H (1993) Memory, amnesia and the hippocampal system. Cambridge, MA: MIT.

Crawford JR, Howell DC (1998) Comparing an individual's test score against norms derived from small samples. Clin Neuropsychol 12:482486. CrossRef

Crawford JR, Garthwaite PH, Gray CD (2003) Wanted: fully operational definitions of dissociations in single-case studies. Cortex 39:357-370. CrossRef Medline

Crawford JR, Garthwaite PH, Porter S (2010) Point and interval estimates of effect sizes for the case-controls design in neuropsychology: rationale, methods, implementations, and proposed reporting standards. Cogn Neuropsychol 27:245-260. CrossRef Medline

Davachi L (2006) Item, context and relational episodic encoding in humans. Curr Opin Neurobiol 16:693-700. CrossRef Medline

Davison AC, Hinkley DV (1997) Bootstrap methods and their applications. Cambridge, UK: Cambridge UP.

Delis DC, Kramer JH, Kaplan E, Ober BA (1987) California Verbal Learning Test: Adult version. Manual. San Antonio: Psychological Corporation.

Desimone R (1996) Neural mechanisms for visual memory and their role in attention. Proc Natl Acad Sci U S A 93:13494-13499. CrossRef Medline

Duchaine BC, Nakayama K (2004) Developmental prosopagnosia and the
Benton Facial Recognition Test. Neurology 62:1219-1220. CrossRef Medline

Duchaine BC, Weidenfeld A (2003) An evaluation of two commonly used tests of unfamiliar face recognition. Neuropsychologia 41:713-720. CrossRef Medline

Efron B (1987) Better bootstrap confidence intervals. J Am Stat Assoc 82: 171-185. CrossRef

Eichenbaum H, Cohen NJ (2001) From conditioning to conscious recollection: memory systems of the brain. New York: Oxford UP.

Eichenbaum H, Yonelinas AP, Ranganath C (2007) The medial temporal lobe and recognition memory. Annu Rev Neurosci 30:123-152. CrossRef Medline

Ezzyat Y, Olson IR (2008) The medial temporal lobe and visual working memory: comparisons across tasks, delays, and visual similarity. Cogn Affect Behav Neurosci 8:32-40. CrossRef Medline

Firestone A, Turk-Browne NB, Ryan JD (2007) Age-related deficits in face recognition are related to underlying changes in scanning behavior. Neuropsychol Dev Cogn B Aging Neuropsychol Cogn 14:594-607. CrossRef Medline

Grill-Spector K, Henson R, Martin A (2006) Repetition and the brain: neural models of stimulus-specific effects. Trends Cogn Sci 10:14-23. CrossRef Medline

Grober E, Sliwinski M (1991) Development and validation of a model for estimating premorbid verbal intelligence in the elderly. J Clin Exp Neuropsychol 13:933-949. Medline

Hannula DE, Althoff RR, Warren DE, Riggs L, Cohen NJ, Ryan JD (2010) Worth a glance: using eye movements to investigate the cognitive neuroscience of memory. Front Hum Neurosci 4:166. CrossRef Medline

Heaton RK, Chelune GJ, Talley JL, Kay GG, Curtiss G (1993) Wisconsin Card Sorting Test (WCST) Manual, revised and expanded. Odessa, FL: Psychological Assessment Resources.

Holdstock JS, Mayes AR, Cezayirli E, Isaac CL, Aggleton JP, Roberts N (2000) A comparison of egocentric and allocentric spatial memory in a patient with selective hippocampal damage. Neuropsychologia 38:410 425. CrossRef Medline

Hurley NC, Maguire EA, Vargha-Khadem F (2011) Patient HC with developmental amnesia can construct future scenarios. Neuropsychologia 49: 3620-3628. CrossRef Medline

Jonides J, Lewis RL, Nee DE, Lustig CA, Berman MG, Moore KS (2008) The mind and brain of short-term memory. Annu Rev Psychol 59:193-224. CrossRef Medline

King JA, Burgess N, Hartley T, Vargha-Khadem F, O'Keefe J (2002) Human hippocampus and viewpoint dependence in spatial memory. Hippocampus 12:811-820. CrossRef Medline

Konkel A, Warren DE, Duff MC, Tranel DN, Cohen NJ (2008) Hippocampal amnesia impairs all manner of relational memory. Front Hum Neurosci 2:15. CrossRef Medline

Lee AC, Yeung LK, Barense MD (2012) The hippocampus and visual perception. Front Hum Neurosci 6:91. CrossRef Medline

Longmore CA, Liu CH, Young AW (2008) Learning faces from photographs. J Exp Psychol Hum Percept Perform 34:77-100. CrossRef Medline

Marr D (1971) Simple memory: a theory for archicortex. Philos Trans R Soc Lond B Biol Sci 262:23-81. CrossRef Medline

Mayes AR, Holdstock JS, Isaac CL, Hunkin NM, Roberts N (2002) Relative sparing of item recognition memory in a patient with adult-onset damage limited to the hippocampus. Hippocampus 12:325-340. CrossRef Medline

Mayes A, Montaldi D, Migo E (2007) Associative memory and the medial temporal lobes. Trends Cogn Sci 11:126-135. CrossRef Medline

Meyers JE, Meyers KR (1996) Rey Complex Figure Test and Recognition Trial: Supplemental Norms for Children and Adolescents. Florida: PAR.

Milner B (1968) Further analysis of the hippocampal amnesic syndrome: 14-year follow-up study of H.M. Neuropsychologia 6:215-234. CrossRef

Montaldi D, Mayes AR (2010) The role of recollection and familiarity in the functional differentiation of the medial temporal lobes. Hippocampus 20:1291-1314. CrossRef Medline

Moses SN, Ryan JD (2006) A comparison and evaluation of the predictions of relational and conjunctive accounts of hippocampal function. Hippocampus 16:43-65. CrossRef Medline

Moses SN, Ostreicher ML, Rosenbaum RS, Ryan JD (2008) Successful 
transverse patterning in amnesia using semantic knowledge. Hippocampus 18:121-124. CrossRef Medline

O'Keefe JA, Nadel L (1978) The hippocampus as a cognitive map. London: Clarendon.

Olsen RK, Moses SN, Riggs L, Ryan JD (2012) The hippocampus supports multiple cognitive processes through relational binding and comparison. Front Hum Neurosci 6:146. CrossRef Medline

Olsen RK, Palombo DJ, Rabin JS, Levine B, Ryan JD, Rosenbaum RS (2013) Volumetric analysis of medial temporal lobe subregions in developmental amnesia using high-resolution magnetic resonance imaging. Hippocampus 23:855-860. CrossRef Medline

O'Reilly RC, McClelland JL (1994) Hippocampal conjunctive encoding, storage, and recall: avoiding a trade-off. Hippocampus 4:661-682. CrossRef Medline

Rabin JS, Braverman A, Gilboa A, Stuss DT, Rosenbaum RS (2012) Theory of mind development can withstand compromised episodic memory development. Neuropsychologia 50:3781-3785. CrossRef Medline

Rabin JS, Carson N, Gilboa A, Stuss DT, Rosenbaum RS (2013) Imagining other people's experiences in a person with impaired episodic memory: the role of personal familiarity. Front Psychol 3:588. CrossRef Medline

Race E, LaRocque KF, Keane MM, Verfaellie M (2013) Medial temporal lobe contributions to short-term memory for faces. J Exp Psychol Gen 142:1309-1322. CrossRef Medline

Reed JM, Squire LR (1997) Impaired recognition memory in patients with lesions limited to the hippocampal formation. Behav Neurosci 111:667675. CrossRef Medline

Rickard TC, Verfaellie M, Grafman J (2006) Transverse patterning and human amnesia. J Cogn Neurosci 18:1723-1733. CrossRef Medline

Rose NS, Olsen RK, Craik FI, Rosenbaum RS (2012) Working memory and amnesia: the role of stimulus novelty. Neuropsychologia 50:11-18. CrossRef Medline

Rosenbaum RS, Carson N, Abraham N, Bowles B, Kwan D, Köhler S, Svoboda E, Levine B, Richards B (2011) Impaired event memory and recollection in a case of developmental amnesia. Neurocase 17:394-409. CrossRef Medline

Rosenbaum RS, Gilboa A, Moscovitch M (2014a) Case studies continue to illuminate the cognitive neuroscience of memory. Ann N Y Acad Sci 1316: 105-133. CrossRef Medline

Rosenbaum RS, Gao F, Honjo K, Raybaud C, Olsen RK, Palombo DJ, Levine B, Black SE (2014b) Congenital absence of the mammillary bodies: a novel finding in a well-studied case of developmental amnesia. Neuropsychologia 65:82-87. CrossRef Medline

Shrager Y, Levy DA, Hopkins RO, Squire LR (2008) Working memory and the organization of brain systems. J Neurosci 28:4818-4822. CrossRef Medline

Smith CN, Jeneson A, Frascino JC, Kirwan CB, Hopkins RO, Squire LR (2014) When recognition memory is independent of hippocampal function. Proc Natl Acad Sci U S A 111:9935-9940. CrossRef Medline

Spreen O, Strauss E (1998) A compendium of neuropsychological tests: administration, norms, and commentary (2nd ed.). New York: Oxford UP.

Squire LR, Wixted JT, Clark RE (2007) Recognition memory and the medial temporal lobe: a new perspective. Nat Rev Neurosci 8:872-883. CrossRef Medline

Stark CE, Squire LR (2003) Hippocampal damage equally impairs memory for single items and memory for conjunctions. Hippocampus 13:281292. CrossRef Medline

Stroop JR (1935) Studies of interference in serial verbal reactions. J Exp Psychol 18:643-662.

Taylor KJ, Henson RN, Graham KS (2007) Recognition memory for faces and scenes in amnesia: dissociable roles of medial temporal lobe structures. Neuropsychologia 45:2428-2438. CrossRef Medline

Turriziani P, Fadda L, Caltagirone C, Carlesimo GA (2004) Recognition memory for single items and for associations in amnesic patients. Neuropsychologia 42:426-433. CrossRef Medline

Warrington EK, Taylor AM (1973) Immediate memory for faces: long- or short-term memory? Q J Exp Psychol 25:316-322. CrossRef Medline

Wechsler D (1997) Wechsler Adult Intelligence Scale III: third edition manual. San Antonio: Psychological Corporation.

Wechsler D (1999) The Wechsler Abbreviated Scale of Intelligence. New York: Psychological Corporation.

Wiggs CL, Martin A (1998) Properties and mechanisms of perceptual priming. Curr Opin Neurobiol 8:227-233. CrossRef Medline 